\title{
Pendidikan Kesehatan Masyarakat Perawatan Payudara pada Ibu Nifas di Posyandu Dewi Sri Pamulang Kota Tangerang Selatan
}

\author{
Ikada Septi Arimurti ${ }^{1}$, Rita Dwi Pratiwi ${ }^{2}$, Wannasta Alayya ${ }^{3}$ \\ STIKes Widya Dharma Husada Tangerang, Jl. Pajajaran No.1, Pamulang Bar., Kec. Pamulang, \\ Kota Tangerang Selatan, Banten $15417^{1,2,3}$ \\ Email: ikadaseptiarimurti@wdh.ac.id ${ }^{1}$
}

\begin{abstract}
ABSTRAK
Data Riskesdas tahun 2018 menyatakan bahwa pada bayi umur 0-5 bulan di Indonesia, proporsi pola pemberian ASI sebanyak 37,3\% ASI ekslusif, sedangkan pada ASI parsial dan ASI predominan masingmasing sebesar 9,3\%, dan 3,3\%. Hal ini menunjukkan bahwa angka ASI eksklusif kita masih tergolong rendah. Perawatan payudara adalah faktor yang berpengaruh terhadap keberhasilan proses menyusui pada ibu nifas, selain faktor lainnya. Penelitian sebelumnya mengungkapkan terdapat hubungan yang signifikan antara perawatan payudara dengan keberhasilan proses menyusui dengan p-value sebesar 0,007. Tujuan pengabdian masyarakat ini adalah memberi edukasi kepada masyarakat khususnya ibu nifas untuk dapat melakukan perawatan payudara pada masa nifasnya sehingga bisa mendukung program ASI eksklusif. Metode pengabdian masyarakat dilakukan melalui ceramah dan simulasi perawatan payudara. Pendidikan kesehatan dilakukan oleh dosen dan mahasiswa STIKes Widya Dharma Husada Tangerang. Kegiatan bertempat di Posyandu Dewi Sri Pamulang Kota tangerang Selatan. Pelaksanaannya pada saat kegiatan posyandu lalu disertakan pendidikan kesehatan dengan tema perawatan payudara pada ibu nifas. Peserta kegiatan sebanyak 15 orang ibu nifas. Terdapat antusiasme warga saat kegiatan berlangsung. Dampak kegiatan ini peserta mengetahui cara melakukan perawatan pada payudara sehingga sangat bermanfaat dalam proses menyusuinya. Harapan selanjutnya adalah kader posyandu juga dapat terus memberikan pendidikan kesehatan mengenai perawatan payudara pada ibu nifas yang belum memahami bagaimana merawat payudara selama proses menyusui.
\end{abstract}

Kata kunci: Perawatan Payudara; Nifas; Pendidikan Kesehatan

\begin{abstract}
Riskesdas data for 2018 states that in infants aged 0-5 months in Indonesia, the proportion of breastfeeding patterns is 37,3\% exclusive breastfeeding, while partial breastfeeding and predominant breastfeedings are $9,3 \%$ and 3,3\%, respectively. This shows that our exclusive breastfeeding rate is still low. Breast care is one of the factors that influence the success of the breastfeeding process in postpartum mothers and other factors. Previous research revealed a significant relationship between breast care and the success of the breastfeeding process with a p-value $=0,007$. This community service aims to provide education to the community, especially postpartum mothers, to carry out breast care during the puerperium so that they can support the exclusive breastfeeding programs. Community service methods are carried out through lectures and simulations of breast care. Health education is carried out by lecturers and students of STIKes Widya Dharma Husada Tangerang. The activity took place at Posyandu Dewi Sri Pamulang, South Tangerang City. It was implemented during the posyandu activities and then included health education with breast care for postpartum mothers. Participants in the activity were about 15 mothers. There was enthusiasm from the residents when the activity took place. The impact of this activity, participants know how to do a treatment on the breast, so it is very beneficial in breastfeeding. The next hope is that posyandu cadres can also continue to provide health education on breast care to mothers who do not understand how to care for the breast during the breastfeeding process.
\end{abstract}

Keywords: Breast Care; Post Partum; Health Education 


\section{PENDAHULUAN}

Air Susu Ibu (ASI) memiliki kandungan gizi dalam jumlah yang besar dan sangat bermanfaat untuk kesehatan bayi. World Health Organization (WHO) merekomendasikan pemberian ASI ekskiusif terhadap bayi selama enam bulan. Data WHO tahun 2016 menunjukkan rata-rata angka pemberian ASI eksklusif di dunia baru berkisar 38 persen. Di Indonesia, capaian ASI eksklusif belum mencapai angka yang ditargetkan. Di Indonesia walaupun sebagian besar ibu (96\%) menyusui anak mereka dalam kehidupan mereka, hanya 42\% dari bayi yang berusia di bawah 6 bulan yang mendapatkan ASI eksklusif (IBI,2018). Berdasarkan data Riskesdas 2018, hasil survei menunjukkan hanya sebanyak 37,3\% ASI ekslusif, 9,3\% ASI parsial, dan 3,3\% ASI predominan pada proporsi pola pemberian ASI bayi umur 0-5 bulan di Indonesia (Kemenkes RI, 2018). Hal ini menunjukkan bahwa angka ASI eksklusif kita masih tergolong rendah.

Banyak faktor yang mempengaruhi angka kejadian ASI eksklusif diantaranya adalah pengetahuan, sikap, ketersediaan fasilitas dan dukungan keluarga (Septiani dkk, 2017). Pengetahuan berhubungan erat dengan perilaku ibu. Dalam hal ini pada ibu nifas yang menyusui bayinya. Saat seorang ibu mengetahui tentang manfaat ASI dan tatalaksana pendukungnya agar ASI eksklusif terpenuhi, maka ibu tersebut akan melakukannya.

Perawatan payudara adalah salah satu faktor yang memiliki pengaruh signifikan terhadap keberhasilan proses menyusui pada ibu nifas, hal ini diungkapkan oleh Wulandari (2017) dalam penelitiannya yang mendapatkan angka p-value sebesar 0,007. Artinya terdapat hubungan yang signifikan antara perawatan payudara dengan keberhasilan proses menyusui. Hal ini sesuai dengan penelitian yang dilakukan oleh Tyfani dkk (2017) di Kota Malang. Hasil penelitian mengungkapkan terdapat hubungan signifikan antara perawatan payudara terhadap kelancaran ASI pada ibu post partum di Kota Malang ( $\mathrm{p}$-value $=0,001$ ).

Menurut Kumalasari (2015) Perawatan payudara sendiri bertujuan untuk (i) Memelihara kebersihan payudara, (ii) Melenturkan puting susu (iii) Mengurangi risiko lecet saat menyusui (iv) Merangsang produksi ASI (v) Mencegah penyumbatan pada payudara.

Tujuan pelaksanaan pengabdian masyarakat ini adalah untuk memberikan edukasi kepada masyarakat khususnya ibu nifas untuk dapat melakukan perawatan payudara pada masa nifasnya sehingga bisa mendukung program ASI eksklusif. 


\section{METODE}

Pada kegiatan promosi kesehatan dengan tema perawatan payudara pada ibu nifas dilakukan oleh tim pengabdian kepada masyarakat yang terdiri dari dosen dan mahasiswa STIKes Widya Dharma Husada Tangerang. Metode pengabdian masyarakat yang digunakan adalah metode ceramah dan dilanjutkan melalui simulasi praktek dengan menggunakan phantom payudara serta alat untuk perawatan payudara. Pengabdian kepada masyarakat ini dilakukan pada hari Kamis, 12 September 2019. Selain dosen terdapat juga mahasiswa semester III pada program studi D III Kebidanan yang ikut berpartisipasi dalam acara ini serta kader posyandu Dewi Sri Pamulang.

\section{HASIL, PEMBAHASAN, DAN DAMPAK}

Acara penyelenggaraan kegiatan pengabdian kepada masyarakat ini dilaksanakan dalam bentuk pendidikan kesehatan di Posyandu Dewi Sri Pamulang. Acara ini didahului dengan kegiatan posyandu seperti biasanya dengan melalui tahapan 5 meja. Setelah semua peserta posyandu melaksanakan kegiatan, mereka lalu dikumpulkan untuk mendengarkan pendidikan kesehatan mengenai cara perawatan payudara yang disampaikan oleh tim pengabdian kesehatan masyarakat prodi D III kebidanan STIKes Widya Dharma Husada Tangerang. Saat memberikan materi, tim pengabdian kepada masyarakat melakukan ceramah dengan menggunakan leaflet/lembar balik sebagai panduan, lalu mempraktekkan cara melakukan perawatan payudara dengan menggunakan phantom payudara. Setelahnya dilakukan sesi tanya jawab yang diisi dengan banyak pertanyaan dari peserta yang antusias. Berikutnya adalah sesi dimana peserta ditunjuk untuk ikut mencoba mempraktekkan tata cara perawatan payudara menggunakan phantom payudara yang ada dan hasilnya sangat baik.

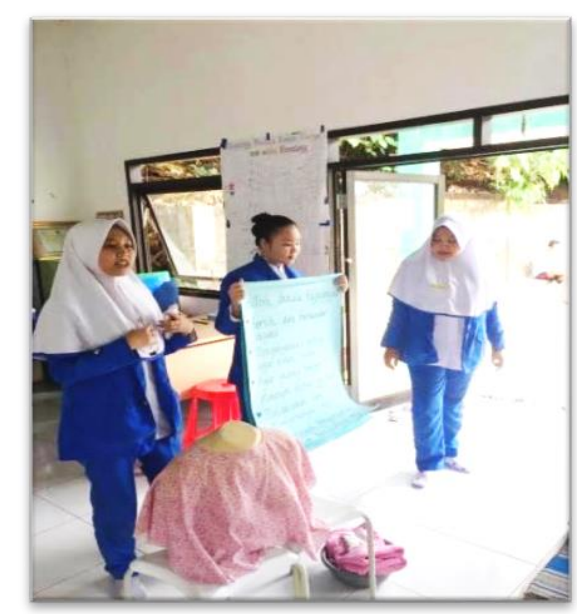

Gambar 1. Penyampaian materi perawatan payudara oleh mahasiswi jurusan kebidanan 


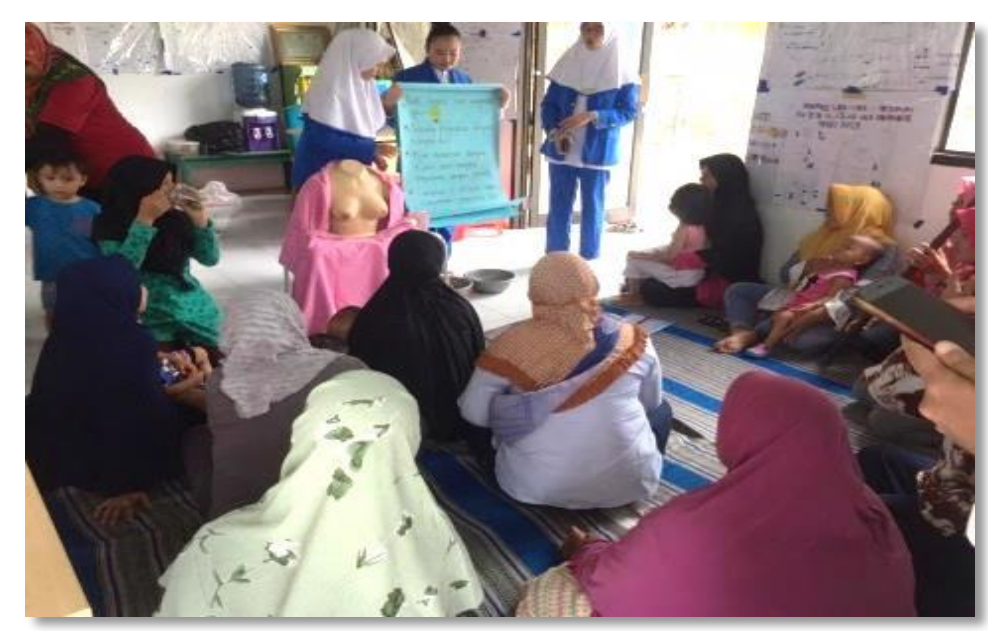

Gambar 2. Simulasi perawatan payudara oleh mahasiswi jurusan kebidanan

Waktu pelaksanaan kegiatan promosi kesehatan ini dilaksanakan berbarengan dengan jadwal posyandu. Kegiatan ini dilakukan melalui penyampaian materi mengenai perawatan payudara dari nara sumber, setelah penyampaian materi dilakukan simulasi tatalaksana perawatan payudara dan ditutup dengan sesi tanya jawab. Peserta yang hadir sangat antusias dalam mengikuti materi dan juga simulasi yang diberikan. Bahkan ada salah satu peserta yang mau mencoba untuk melakukan perawatan payudara di phantom yang telah disediakan.

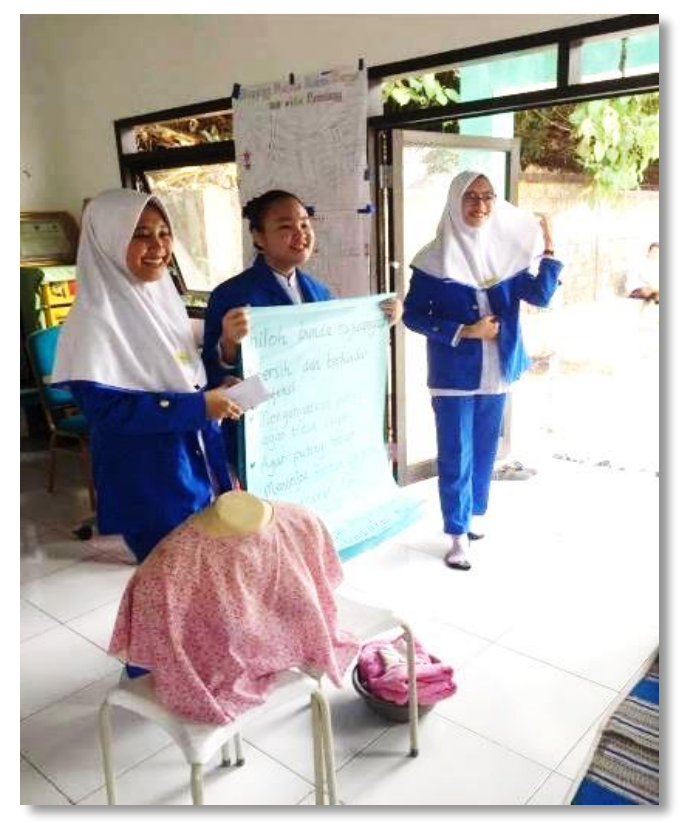

Gambar 3. Sesi tanya jawab 


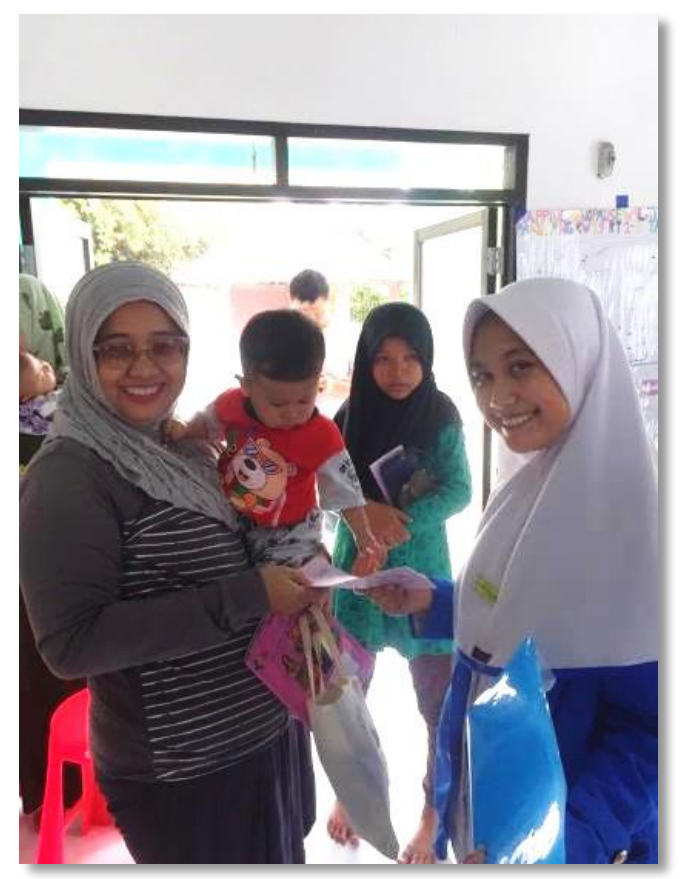

Gambar 4. Pembagian leaflet

Dampak kegiatan ini peserta mengetahui cara melakukan perawatan pada payudara sehingga sangat bermanfaat dalam proses menyusuinya dan mendukung program ASI eksklusif.

\section{SIMPULAN}

Kegiatan ini dapat berlangsung baik dan lancar. Diharapkan kegiatan serupa dapat secara berkesinambungan dilakukan baik oleh kader maupun oleh mahasiswa dari STIKes Widya Dharma Husada Tangerang. Dari kegiatan ini masyarakat khususnya ibu nifas menjadi tahu bagaimana cara melakukan perawatan pada payudara sehingga sangat bermanfaat dalam proses menyusuinya. Saran dari masyarakat yang menanggapi dengan baik, mereka menginginkan agar kegiatan seperti ini dilakukan secara rutin sesuai dengan jadwal posyandu serta topik-topik yang diberikan beraneka ragam sehingga menambah pengetahuan masyarakat dan juga dapat dijadikan sebagai kontribusi STIKes dalam pengabdian kepada masyarakat di wilayah Pamulang Kota Tangerang Selatan.

\section{UCAPAN TERIMAKASIH}

Terima kasih kami haturkan kepada Ketua STIKes Widya Dharma Husada Tangerang; Ketua jurusan DIII kebidanan STIKes Widya Dharma Husada Tangerang; Ibu kader Posyandu Dewi Sri serta pihak-pihak yang terlibat dalam kegiatan pendidikan kesehatan masyarakat perawatan payudara pada ibu nifas ini. 


\section{DAFTAR PUSTAKA}

IBI (2018). Artikel: Pekan ASI Sedunia. www.ibi.org.

Kemenkes RI. (2018). Menyusui Sebagai Dasar Kehidupan. Jakarta: Infodatin Kemenkes RI.

Kumalasari, Intan. (2015). Panduan Praktek Laboratorium dan Klinik Perawatan Antenatal, Intranatal, Post natal, Bayi Baru Lahir dan Kontrasepsi. Jakarta: Salemba Medika.

Septiani, Hanulan., Budi, Artha., Karbito. (2017). Faktor-faktor yang Berhubungan dengan Pemberian ASI Eksklusif Oleh Ibu Menyusui yang Bekerja Sebagai Tenaga Kesehatan. Aisyah Jurnal Ilmu Kesehatan 2 (2012), hal.159-174.

Tyfani, Maria Beatrix., Utamu, Ngesti., Susmini. (2017). Hubungan Perawatan Payudara Terhadap Kelancaran ASI Pada Ibu Post Partum Di Kelurahan Tlogomas Kota Malang. Nursing News Vol.2, No.1, 2017.

Wulandari, Catur. (2017). Hubungan Perawatan Payudara Pada Ibu Post Partum Dengan Kelancaran Pengeluaran ASI Di Desa Galak Ponorogo. Jurnal Delima Harapan Vol.9, No. 8 , Agustus 2017-Januari 2018. 